\title{
PROTOTYPE KAMUS ELEKTRONIK BAHASA DAERAH LUBUK LINGGAU BERBASIS ANDROID
}

\author{
Muhammad Nasir ${ }^{1}$, Vivi Sahfitri $^{2}$ \\ Universitas Bina Darma ${ }^{1,2}$ \\ Jalan Jenderal Ahmad Yani No.3 Palembang \\ Sur-el : nasir@binadarma.ac.id ${ }^{1}$, vivi_sahfitri@binadarma.ac.id ${ }^{2}$
}

\begin{abstract}
The development of the era has brought various changes in various areas of human life, one of which is the use of regional language. Lubuk Linggau is one of the areas in South Sumatera that has a distinctive regional language. Nowadays, the use of regional language has begun to be forgotten by the local people. The development of the era with the advancement of technology makes more people using Indonesian language in communicating with each other. This research aims to build an electronic dictionary of regional languages based on Android efforts to help local governments who are trying to preserve the culture of the region, one of which is regional language. Application will be built using prototype system development method. Application that produced is a dictionary language the area of a city Lubuklinggau based android, that can translate said the basis of of Indonesian - Lubuklinggau including the contrary. The resulting Output is a translation text form of a vocabulary meaning to be known.
\end{abstract}

Keywords: Electronic dictionary, Prototype, regional language, Android

Abstrak : Kemajuan zaman telah membawa berbagai perubahan dalam berbagai bidang kehidupan manusia, salah satunya adalah penggunaan bahasa daerah. Lubuk Linggau merupakan salah satu daerah di Sumatera Selatan yang memiliki bahasa Khas daerah. Saat ini penggunaan bahasa daerah terebut sudah mulai dilupakan oleh masyarakat daerah tersebut. Kemajuan zaman yang diiringi kemajuan teknologi membuat masyarakat lebih banyak menggunakan bahasa indonesia dalam berkomunikasi satu sama lain. Penelitian ini bertujuan untuk membangun sebuah kamus elektronik bahasa daerah lubuk linggau berbasis anrdoid sebagai upaya membantu pemerintah setempat yang sedang berusaha melestarikan budaya daerah tersebut salah satunya adalah bahasa daerah. Aplikasi akan dibangun dengan menggunakan metode prototype sebagai metode pengembangan sistem. Aplikasi kamus elektronik bahasa daerah Lubuk Linggau berbasis Android yang dihasilkan dapat menterjemahkan jata dasar dari bahasa Indonesia - Lubuk Linggau dan sebaliknya. Output yang dihasilkan adalah bentuk text terjemahan dari kosakata yang ingin diketahui artinya.

Kata kunci: Kamus Elektronik, Prototype, Bahasa daerah, Android

\section{PENDAHULUAN}

Indonesia merupakan negara kepulauan yang memiliki banyak suku bangsa, budaya dan bahasa. Hampir semua daaerah di Indonesia memiliki bahasa daerah masing-masing. Indonesia memiliki kurang lebih 700 ragam bahasa daerah yang digunakan diberbagai daerah di Indonesia[1]. Meskipun demikiaan untuk mempersatukan perbedaan bahasa disetiap daerah tersebut, bahasa Indonesia merupakan bahasa pemersatu bangsa. Bahasa yang dimiliki masing-masing daerah merupakan media komunikasi yang digunakan untuk mengadakan hubungan dalam pergaulan sehari-hari masyarakat didaerah tersebut serta berfungsi sebagai sarana untuk menyampaikan informasi [2].

Namun saat ini penggunaan bahasa daerah sudah mulai mengalami penurunan sebagai alat komunikasi sehari-hari di daerah. Salah satu 
faktor penyebabnya adalah berubahnya kebiasaan generasi muda yang lebih menyukai berkomunikasi dengan menggunakan bahasa Indonesia dari pada menggunakan bahasa daerah [3]. Lubuk Linggau merupakan salah satu kabupaten di Provinsi Sumatera Selatan yang memiliki bahasa khas yaitu bahasa sindang atau lebih sering didengar bahasa coul. Saat ini bahasa asli daerah tersebut sudah hampir terlupakan karena masyarakat lebih sering menggunakan bahasa Indonesia dalam berkomunikasi sehari-hari.

Melestarikan Bahasa daerah yang hampir terlupakan sangat penting untuk dilakukan seiring dengan berkembangnya teknologi yang semakin pesat. Saat ini kehidupan manusia tidak bisa lepas dari sentuhan teknologi. Profesi apapun diberbagai bidang, teknologi akan selalu memiliki peran penting dalam era globalisasi saat ini, salah satunya dalah Teknologi Komunikasi. Adanya perkembangan teknologi Informasi memberikan berbagai kemudahan bagi semua orang terutama dalam membantu meyelesaikan pekerjaan, mempermudah komunikasi dan yang terpenting dengan teknologi informasi dapat memberikan kemudahan dalam memperoleh informasi secara lebih luas. Saat ini kebutuhan informasi sangat penting diberbagai bidang kehidupan, salah satu manfaat dari ketepatan dan kecepatan informaasi adalah dapat membantu mengambil keputusan yang cepat dan tepat saat ini atau saat mendatang[4].

Penelitian ini bertujuan untuk merancang sebuah Prototype Kamus Elektronik Bahasa Daerah Lubuk Linggau Berbasis Android.
Dengan kemajuan teknologi komunikasi saat ini dapat memberikan kemudahan dalam upaya melestarikan budaya yang hampir punah karena kemajuan zaman salah satunya dalam melestarikan bahasa khas daerah tertentu melalui aplikasi khusus yang dapat membantu pencarian kosa kata dalam bahasa daerah sebagai pengganti buku atau kamus konvensional yang berukuran besar dan tebal yang dapat dibawa kemana saja dan dilihat kapan saja. Kamus dapat diartikan sebagai buku acuan yang memuat kata dan ungkapan yang biasanya disusun menurut abjad dan disertai keterangan tentang makna, pemakaian dan terjemahannya. Kamus dapat merupakan buku rujukan yang memberikan keterangan tentang makna kata yang dapat membantu seseorang mengenal katakata baru [5].

Aplikasi khusus yang dapat memberikan kemudahan dalam memahami bahasa khas suatu daerah dapat disebut sebagai Kamus Elektronik. Kamus elektronik memberikan kemudahan dalam melakukan pencarian makna kata yang sepadan baik dari Bahasa Indonesia ke Bahasa Daerah maupun sebaliknya. Kamus elektronik mengacu pada kamus yang digunakan secara elektronik baik berupa Compact Disc (CD) maupun secara online. Perbedaaan antara kamus cetak dan elektronika adalah bahwa pada kamus elektronik data yang dugunakan dapat lebih banyak dengan kapasitas yang lebih besar serta dapat langsung dilakukan operasi penterjemahan untuk mengetahui makna kata yang diperlukan.

Aplikasi yang akan dirancang dan dikembangkan dalam penelitian ini adalah aplikasi berbasis mobile yang akan berjalan 
diatas platform andorid sebagai Sistem Operasinya. Android merupakan Mobile Operating System, yaitu Sistem Operasi middleware dan aplikasi inti [6].

Penelitian yang berkaitan dengan kamus elektronik sudah cukup banyak dilakukan antara lain penelitian yang dilakukan oleh Imaddudin Aziz dan Hani Harafani (2016) dengan Aplikasi Kamus Bahasa Betawi berbasis Android Menggunakan Metode Sequencial Search yang menghasilkan sebuah kamus elektronik yang dapat melakukan fungsi pencarian kosakata bahasa Betawi secara elektronik, menampilkan arti dari kosakata bahasa Betawi dalam Bahasa Indonesia berbasis Mobile Android [7]. Penelitian lain dilakukan oleh Lady O Kasema, dkk (2018) dengan judul Penelitian Aplikasi Kamus Bahasa Daerah Pasan Berbasis Android dengan hasil penelitian adalah sebuah kamus elektronik yang dapat mempermudah masyarakat dalam mencari terjemahan kata dalam bahasa Indonesia ke bahasa Pasan atau sebaliknya dengan menggunakan metode Rapid Application Development (RAD)[8].

Penelitian sejenis lainnya dilakukan oleh Bayu Sulistio, Dkk (2019) dengan judul penelitian Aplikasi Kamus Bahasa Taliabu Berbasis Android Dengan Menggunakan Metode Binary Search. Hasil Penelitian berupa aplikasi Kamus Elektroni yang memberikan kemudahan bagi pengguna dalam mengetahui arti terjemahan kosakata dalam bahasa Indonesia ke Bahasa Taliabu atau sebaliknya, disertai dengan contoh kalimat dalam bahasa Taliabu [9]. Penelitian lain dilakukan oleh Ika M.H Martoyo, Dkk (2018) dengan judul Penelitian Pembuatan Aplikasi
Kamus Bahasa Siau yang menghasilkan aplikasi Kamus Elektronik untuk melakukan pencarian kata dalam bahasa Siau ke bahasa Indonesia dan Sebaliknya yang dapat dijalankan pada Smartphone berbasis Android [10].

\section{METODOLOGI PENELITIAN}

Metode Penelitian merupakan tahapan pelaksanaan penelitian agar proses yang dilakukan dalam kegiatan penelitian dapat terstruktur dengan baik sehingga tujuan peneitian dapat tercapai dan sesuai dengan apa yang diharapkan. Penelitian ini menggunaka metode Development Research yaitu metode yang bertujuan untuk mengembangkan research yang sudah dilakukan atau sudah diketahui sebelumnya [11].

\subsection{Metode Pengembangan Sistem}

Metode pengembangan sistem yang digunakan untuk mengembangkan aplikasi kamus elektronik bahasa daerah Lubuk LInggau berbasis Andorid ini adalah metode Prototype. Model prototype (prototyping model) dimulai dari mengumpulkan kebutuhan pelanggan terhadap perangkat lunak yang akan dibuat [12]. Metode Prototyping adalah sebuah paradigma baru untuk membangun atau mengembangkan sistem atau aplikasi yang merupakan revolusi dalam pengembangan sistem informasi bukan hanya sekedar evoluasi dari metode pengembangan sistem yang sudah ada sebelumnya [13]. Tahapan-tahapan yang ada pada metode prototype terdiri dari [13] ; 


\section{Listen to Customer}

Merupakan tahap pengumpulan data yang berkaitan dengan kebutuhan dari sistem yang akan dibangun atau dikembangkan dengan mendengarkan langsung kebutuhan dari pelanggan. Agar sistem yang dihasilkan sesuai dengan kebutuhan, maka lebih dahulu harus diketahui proses bisnis yang berjalan sehingga akan dapat diketahui masalah yang terjadi

\section{Build/Revise Mock Up}

Merupakan tahap perancangan dan pembuatan prototype System yang dibutuhkan sesuai dengan keinginan customer yang sudah diketahui pada tahap sebelumnya.

\section{Customer test to driver mock up}

Tahap ini merupakan tahap pengujian terhadap prototype sistem yang telah dibuat oleh customer. Hasil dari pengujian akan menjadi evaluasi terhadap kekurangankekurangan berdasarkan kebutuhan dari customer.

Tahapan pada Metode Prototype dapat digambarkan seperti pada gambar 1 .

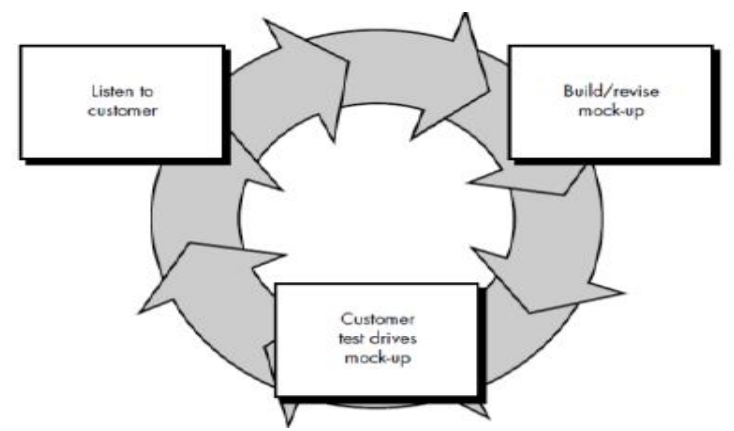

Gambar 1. Prototype Model [13]

\subsection{Metode Pengumpulan Data}

Data merupakan bagian terpenting dalam sebuah Penelitian. Data yang berasal dari sumber yang dipercaya akan membantu dalam menyelesaikan tahapan penelitian untuk mencapai tujuan penelitian yang diharapkan. Metode pengumpulan data yang digunakan dalam penelitian ini meliputi; 1) Metode Observasi, merupakan Teknik Pengamatan yang dilakukan langsung terhadap objek serta mengumpulkan data-data dan informasi yang dibutuhkan dalam pelaksanaan penelitian. Pengamatan dilakukan secara teliti dengan mencatat secara sistematis kejadian-kejadian, perilaku, objek-objek yang dilihat dan hal-hal lainnya [14], 2) Literature Review, atau studi pustaka yaitu metode pengumpulan data melalui data sekunder yang diperoleh melalui membaca, mempelajari Text book, jurnal ilmiah, makalah penelitian atau referensi lain yang dapat mendukung dan berkaitan dengan permasalahan dalam penelitian, 3) Wawancara, merupakan pengumpulan data melalui pencarian keterangan atau informasi langsung dari narasumber yang memahami objek penelitian dengan melakukan Tanya jawab langsung (tatap muka) antara penanya dan responden yang menjadi narasumber untuk mendapatkan informasi yang dibutuhkan.

\section{HASIL DAN PEMBAHASAN}

\subsection{Perancangan Sistem}

Perancangan Sistem merupakan langkah awal yang dilakukan sebelum membangun sebuah sistem berbasis Komputer. Setelah diketahui kebutuhan akan sistem yang akan dibangun melalui tahapan pengumpulan data, maka langkah selanjutnya adalah membuat 
rancangan sistem yang akan dibangun tersebut. Rancangan sistem yang dihasilkan akan menjadi gambaran proses yang terjadi dalam sistem yang aan dibangun nantinya. Tahapan perancangan sistem menjadi bagian terpenting dalam membangun atau mengembangkan sebuah sistem atau aplikasi berbasis komputer, karena dalam tahapan ini juga akan dapat dispesifikasikan aspek aspek kebutuhan dari sistem yang akan dibangun baik hardware maupun software nya.

Rancangan Sistem untuk membangun Perangkat Lunak Aplikasi Kamus Elektronik Bahasa Daerah Lubuk Linggau bebasis Android ini dibuat dengan menggunakan tools Diagram Unified Modelling Language (UML) yang akan memuat rancangan sistem terdiri dari Use Case Diagram, Activity Diagram dan Class Diagram.

\section{a) Use Case Diagram}

Diagram Use Case di rancang untuk menggambarkan hubungan yang terjadi antara aktor-aktor yang terlibat dengan sistem nantinya. Gambar 2 menunjukkan Use Case diagram sistem.

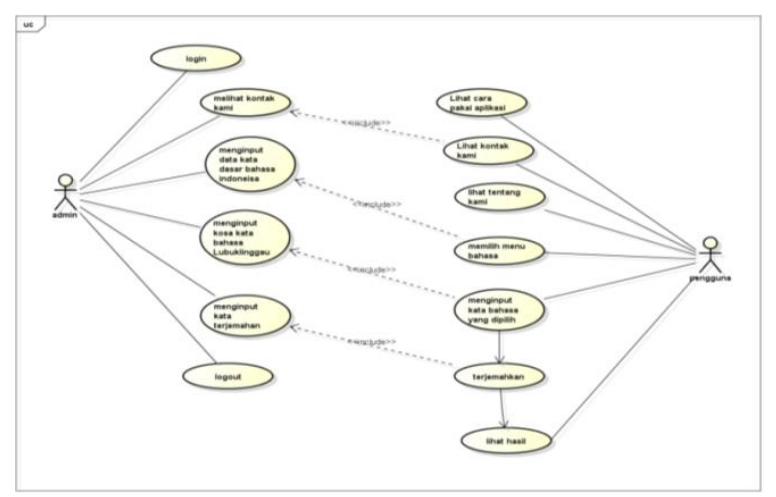

\section{Gambar 2. Use case Diagram}

Berdasarkan gambar 2 dapat diketahui bahwa terdapat 2 aktor yang ada dalam sistem yaitu Admin yang memiliki hak akses untuk mengelola data kamus elektornik yang akan dibangun dan Pengguna (user) yang dapat mengakses kamus elektronik untuk mencari kata yang diinginkan.

b) Activity Diagram

Diagram Activity menggambarkan semua aktivitas yang dilakukan oleh aktor yang terlibat dalam sistem terhdapa sistem yang dibangun. Gambar 3 dan gambar 4 menunjukan rancangan activity diagram sistem yang dibangun.

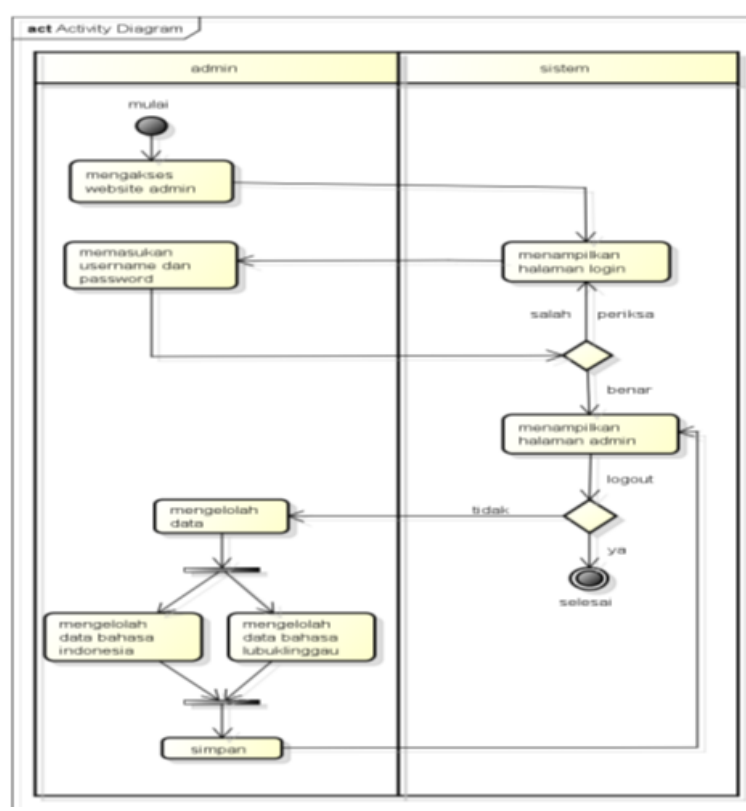

Gambar 3. Activity Admin dan Sistem

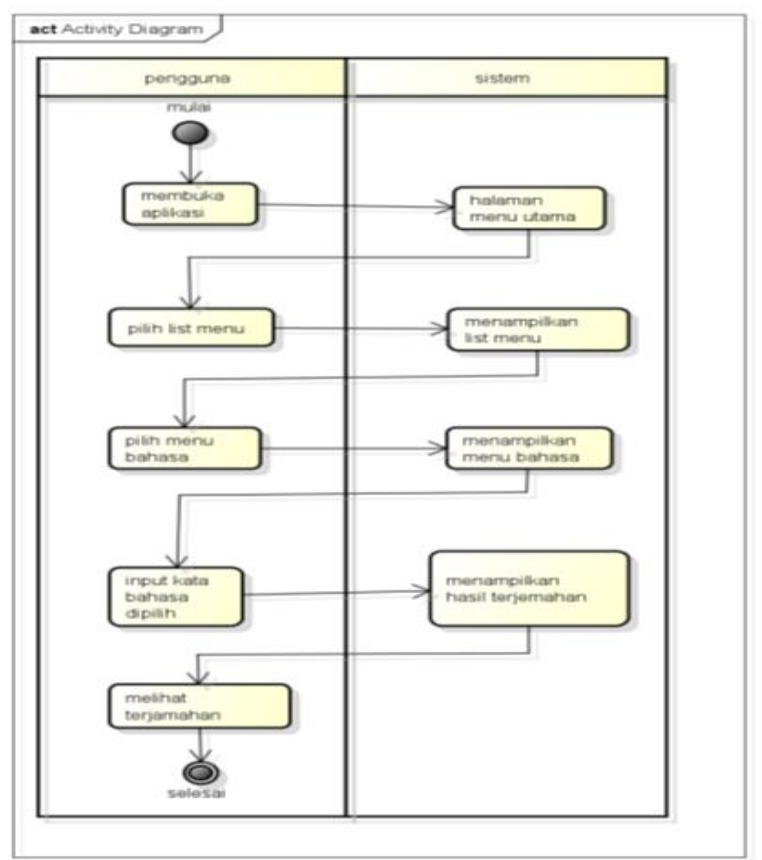

Gambar 4. Activity Pengguna dan Sistem 


\section{c) Class Diagram}

Hasil data sistem ini terdiri atas kumpulan file (table) yang saling berhubungan dalam sebuah basis data disebuah sistem komputer yang memungkinkan untuk mengakses dan memanifulasi file-file (table-table) tersebut. Class diagram merupakan diagram untuk menampilkan hubungan antar setiap tabel tersebut.

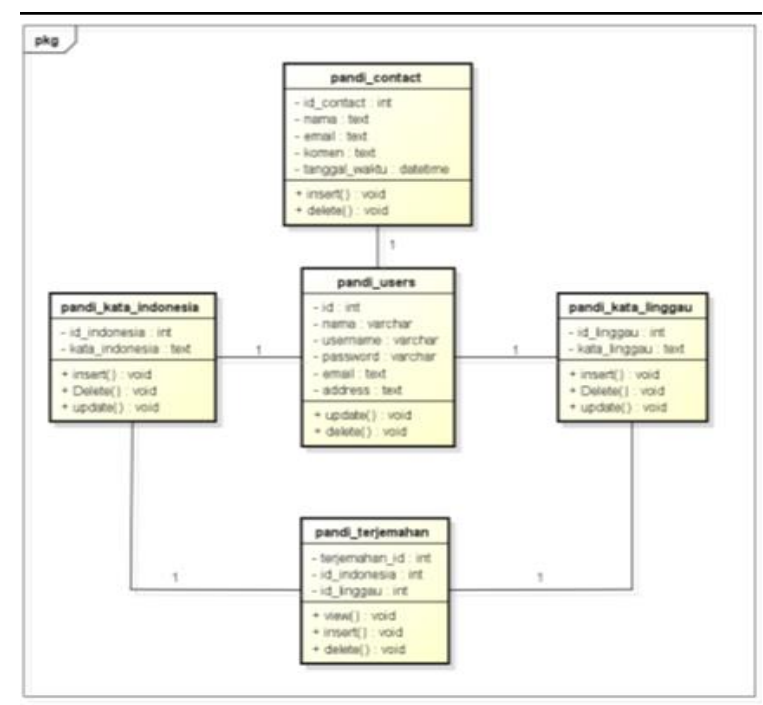

Gambar 5. Class Diagram System

\subsection{User Interface}

User Interface merupakan antarmuka yang menjadi media perantara antara sistem dengan pengguna sistem tersebut. User Interface menghubungkan antara sistem dengan pengguna sistem tersebut. Sebelum menjadi antarmuka yang siap digunakan dan user friendly perlu dilakukan perancangan antarmuka agar semua keinginan pengguna dapat diakomodasi sehingga sistem yang dibangun nantinya mudah dipahami dan digunakan. Untuk merancang antarmuka yang baik, perlu untuk diperhatikan prinsip-prinsip User Compatibility, Product Compatibility, Task Compatibility, Work Flow Compatibility, Consistency and Familiarity,
Control,Flexibility and Responsiveness, Invisible Technology, Robustness, Ease of learning [15].

A. Menu Administrator.

Gambar 6,7,8, dan 9 menampilkan menu sistem yang dikelola administrator untuk mengupdate informasi yang berkaitan dengan Aplikasi Kamus Elektronik Bahasa Daerah Lubuk Linggau Berbasis Android.

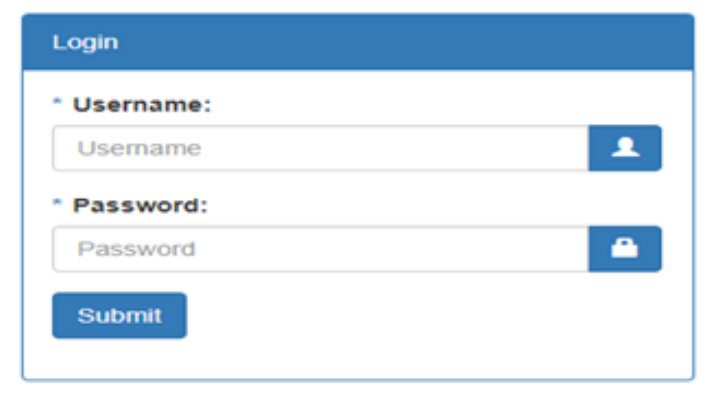

Gambar 6. Halaman Login Admin

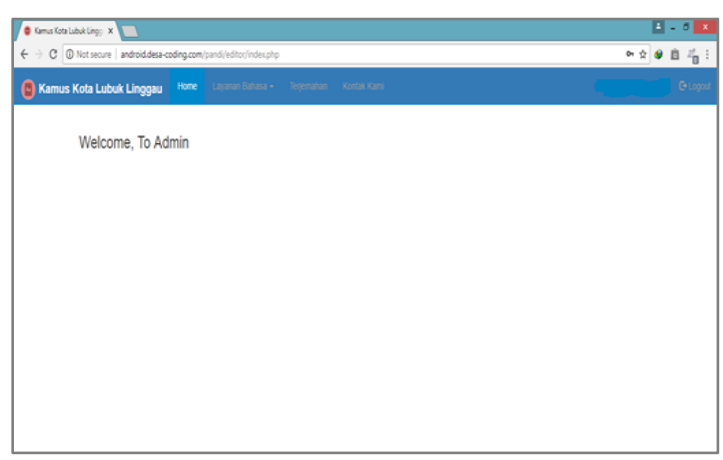

\section{Gambar 7. Halaman Admin}

Pada halaman admin terdapat 4 menu yaitu menu Home, Layanan Bahasa yang berfungsi menginputkan kata untuk kamus, terbagi 2 yaitu layanan bahasa Indonesia dan layanan bahasa lubuk linggau, Terjemahan dan Kontak kami.

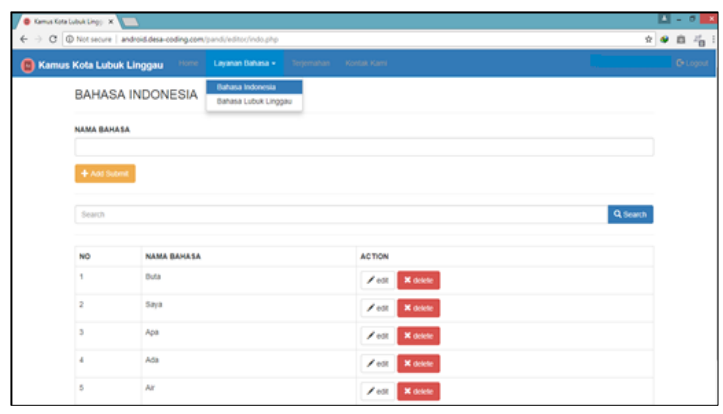

Gambar 8. Halaman Layanan Bahasa 


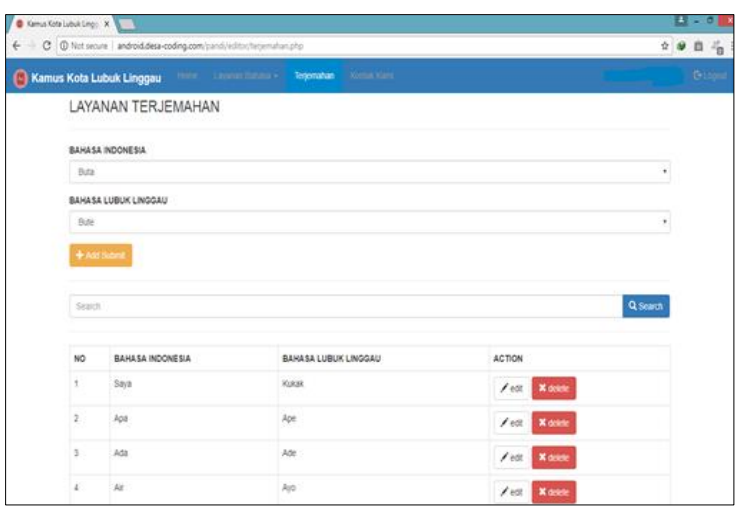

Gambar 9. Halaman Terjemahan

Halaman Terjemahan merupakan halaman yang digunakan untuk mengelola data kata dasar bahasa Indonesia dan Kosa Kata Bahasa Daerah Lubuk Linggau.

\section{B. Menu User}

Menu User adalah bagian antarmuka yang digunakan oleh user (pengguna) untuk berinteraksi dengan sistem. Pada bagian menu ini, pengguna dapat menggunakan aplikasi untuk mencari informasi yang diinginkan terkait dengan Bahasa daerah lubuk linggau. Menu pada pengguna dapat diakses melalui smartphone berbasis android. Beberapa tampilan untuk halaman menu pengguna dapat dilihat pada gambar 10,11,12,13, dan 14 .

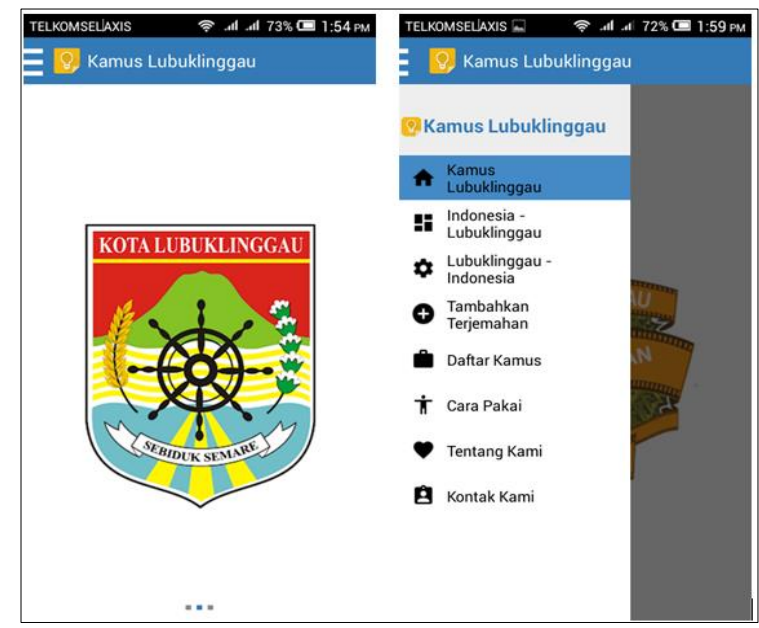

Gambar 10. Halaman Utama Sistem

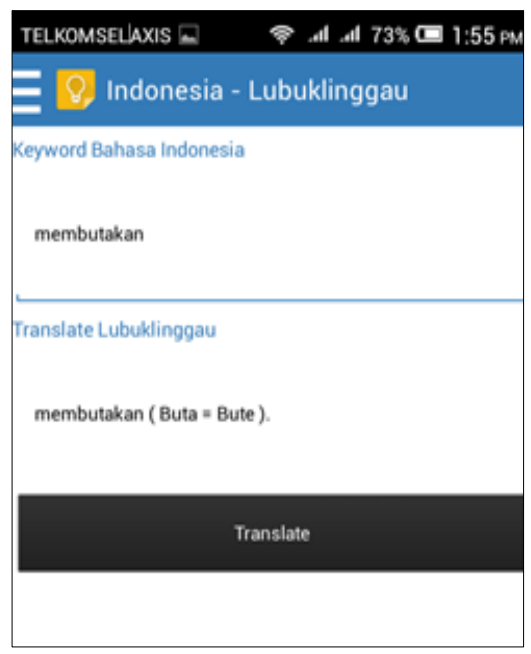

Gambar 11. Halaman menu Indonesia -Lubuk Linggau

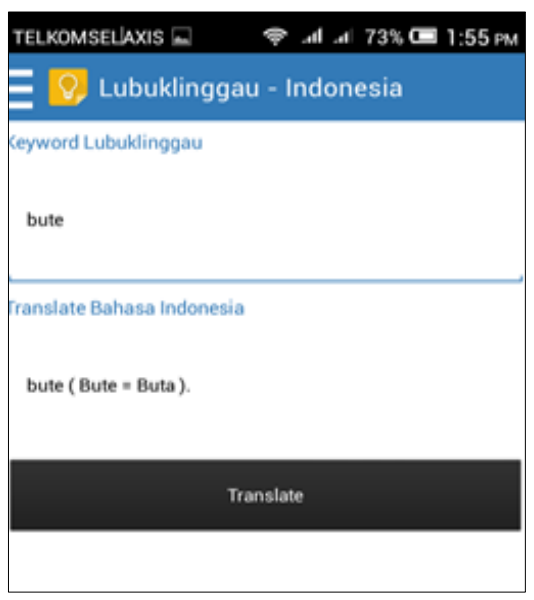

Gambar 12. Halaman menu Lubuk Linggau -Indonesia

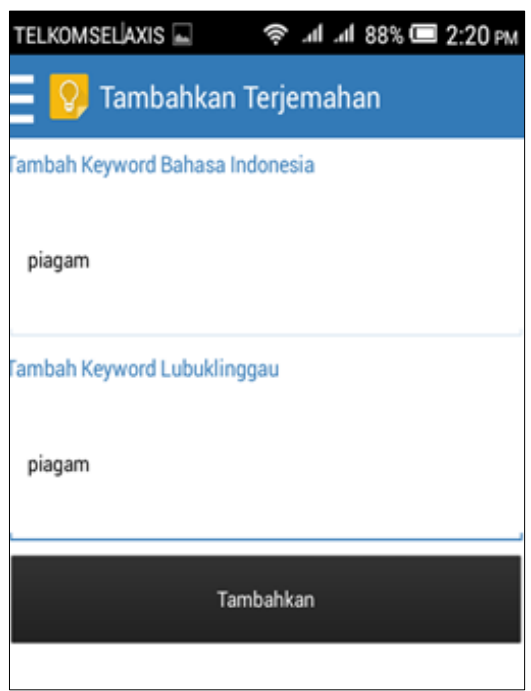

Gambar 13. Halaman Tambahkan Terjemahan 


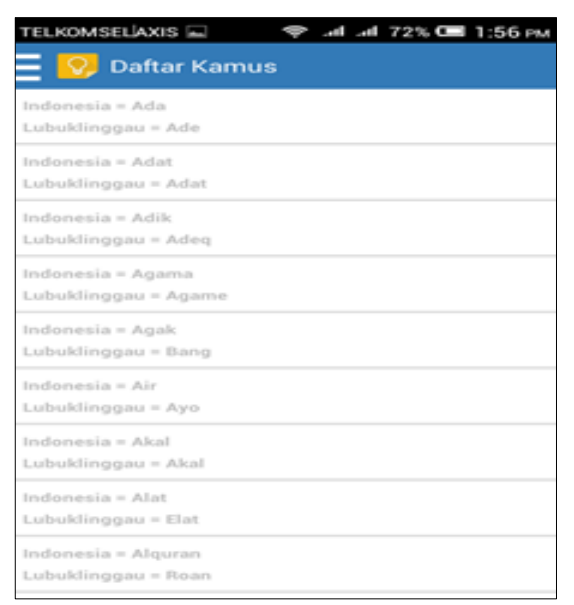

\section{Gambar 14. Halaman Daftar Kata berdasarkan abjad}

\subsection{Pengujian Sistem}

Pengujian sistem dilakukan untuk mengetahui apakah sistem yang dibangun dapat berjalan dengan baik sesuai dengan rencana yang sudah dirancang sebelumnya atau tidak. Untuk melakukan pengujian sistem digunakan metode Balck Box. Black box merupakan metode pengujian perangkat lunak yang menguji kinerja fungsi (fungsionalitas) aplikasi yang bertentangan dengan struktur internal atau kerja.

Tabel 1. Pengujian Black Box Testing Pada

\begin{tabular}{|c|c|c|}
\hline \multicolumn{3}{|c|}{ Sistem User } \\
\hline Fitur & Keterangan & Hasil \\
\hline Menu Home & $\begin{array}{l}\text { Sistem dapat } \\
\text { menampilkan menu } \\
\text { home dan list menu pada } \\
\text { kamus bahasa daerah kota } \\
\text { Lubuklinggau }\end{array}$ & Berhasil \\
\hline $\begin{array}{l}\text { Menu } \\
\text { Indonesia - } \\
\text { Lubuklinggau }\end{array}$ & $\begin{array}{l}\text { Sistem dapat } \\
\text { menampilkan menu } \\
\text { Indonesia - Lubuklinggau }\end{array}$ & Berhasil \\
\hline $\begin{array}{l}\text { Menu } \\
\text { Lubuklinggau } \\
\text { - Indonesia }\end{array}$ & $\begin{array}{l}\text { Sistem dapat } \\
\text { menampilkan menu } \\
\text { Lubuklinggau - Indonesia }\end{array}$ & Berhasil \\
\hline $\begin{array}{l}\text { Menu Cara } \\
\text { Pakai }\end{array}$ & $\begin{array}{l}\text { Sistem dapat } \\
\text { menampilkan menu cara } \\
\text { pakai aplikasi kamus } \\
\text { bahasa daerah kota } \\
\text { Lubuklinggau }\end{array}$ & Berhasil \\
\hline $\begin{array}{l}\text { Menu Tentang } \\
\text { Kami }\end{array}$ & $\begin{array}{l}\text { Sistem dapat } \\
\text { menampilkan menu } \\
\text { tentang kami }\end{array}$ & Berhasil \\
\hline $\begin{array}{l}\text { Menu Kontak } \\
\text { Kami }\end{array}$ & $\begin{array}{l}\text { Sistem dapat } \\
\text { menampilkan menu } \\
\text { kontak kami }\end{array}$ & Berhasil \\
\hline
\end{tabular}

Tabel 2. Tabel Pengujian Black Box Testing pada Sistem Admin

\begin{tabular}{|c|c|c|}
\hline Fitur & Keterangan & Hasil \\
\hline Login & $\begin{array}{l}\text { Sistem dapat melakukan } \\
\text { login. Ada notifikasi login } \\
\text { gagal jikalau ada kesalahan } \\
\text { username dan password }\end{array}$ & Berhasil \\
\hline Menu Home & $\begin{array}{l}\text { Sistem dapat menampilkan } \\
\text { menu home pada aplikasi } \\
\text { web admin }\end{array}$ & Berhasil \\
\hline Menu & Sistem dapat menampilkan & Berhasil \\
\hline Layanan & menu layann bahasa & \\
\hline Bahasa & Indonesia & \\
\hline Indonesia & & \\
\hline Menu & Sistem dapat menampilkan & Berhasil \\
\hline Layanan & menu layanan bahasa & \\
\hline Bahasa & Lubuklinggau & \\
\hline Lubuklinggau & & \\
\hline Menu & Sistem dapat menampilkan & Berhasil \\
\hline Terjemahan & $\begin{array}{l}\text { menu terjemahan pada } \\
\text { aplikasi } w e b \text { admin }\end{array}$ & \\
\hline $\begin{array}{l}\text { Menu Kontak } \\
\text { Kami }\end{array}$ & $\begin{array}{l}\text { Sistem dapat menampilkan } \\
\text { menu kontak kami }\end{array}$ & berhasil \\
\hline Logout & $\begin{array}{l}\text { Sistem dapat menampilkan } \\
\text { halaman logout }\end{array}$ & Berhasil \\
\hline
\end{tabular}

Berdasarkan hasil pengujian pada tabel 1 dan 2 yang dilakukan untuk sistem Bagi Pengguna (user) dan Sistem bagi Admin dapat diketahaui bahwa aplikasi dapat berjalan dengan baik sesuai dengan rancangan sistem yang sudah dibuat.

\section{KESIMPULAN}

Penelitian ini menghasilkan sebuah prototype Kamus Elektronik Bahasa Daerah Lubuk Linggau berbasis Android yang dapat mempermudaha pengguna untuk mengetahui arti terjemahan kosakata bahasa Indonesia ke bahasa Lubuk Linggau atau sebaliknya. Aplikasi ini dibangun sesederhana mungkin agar dapat membantu siapa saja yang ingin belajar atau pun lebih memahami Bahasa Lubuk Lingau dengan mencari kosa kata dengan cepat. Aplikasi ini juga dapat menjadi salah satu upaya dalam melestarikan budaya daerah khususnya bahasa 
khas daerah Lubuk Linggau agar tidak hilang karena perubahan zaman dan kebiasaan masyarakat asli daerah yang mulai berubah saat ini. Kosa kata dalam kamus elektronik ini dapat terus diperbaharui sehingga akan semakin banyak menyimpan kosa kata daerah lubuk Linggau. Kedepannya, Prototype yang dibangun dapat dikembangkan menjadi lebih baik dengan data dan informasi yang semakin lengkap serta tampilan yang lebih menarik.

\section{DAFTAR PUSTAKA}

[1] A. Muhyidin, Masa Depan Bahasa Indonesia Sebagai Bahasa Pemersatu Bangsa Dalam Bingkai Multikukulturalisme. 2009.

[2] I. N. Farida, "Aplikasi Kamus IndonesiaJawa Berbasis Android," Nusantara of Engineering,. Vol. 2, no. 1, pp. 1-5, 2015.

[3] D.E. Kurniawan, dkk. 2013. Aplikasi Kamus Aneka Bahasa Daerah Berbasis Smartphone Android. [online] Available: http://p2m.polibatam.ac.id/wpcontent/.../01/ ICT_DwiElyKurniawan.v2.pdf [accessed: 21 Juni 2020]

[4] Sutabri, Tata. 2012. Analisis Sistem Informasi. Andi. Yogyakarta.

[5] A. N. Arrasyid, "Aplikasi Kamus Bahasa Daerah Tolaki Berbasis Android," Jurnal Sistem Informasi Dan Teknik Komputer Catur Sakti, Vol. 1, no. 1, pp. 62-68, 2016.

[6] Safaat, Nazzarudin. Pemrogramman Aplikasi Mobile Smartphone dan Tablet PC, Informatika : Bandung. 2014

[7] Aziz, Imaddudin dan Harafani, Hani., " Aplikasi Kamus Bahasa Betawi Berbasis Android Menggunakan Metode Sequencial Search,"Jurnal Penelitian Ilmu Komputer, System Embedded \& Logic, Vol. 4, No.1, pp. 27-35, 2016.

[8] Kasema, Lady O., Dkk, "Aplikasi kamus bahasa daerah pasan Berbasis android, " Jurnal Teknik Informatika, Vol.13, No.2, pp. 1-6, 2018.
[9] Sulistio, Bayu Salkin., dkk, “ Aplikasi Kamus Bahasa Taliabu Berbasis Android Dengan Menggunakan Metode Binary Search," Jurnal Informatika dan Ilmu Komputer (JIKO), vol. 2, No. 2, pp. 67-72, 2019.

[10] Martoyo, Ika M.H., Dkk, "Pembuatan Aplikasi Kamus Bahasa Daerah Siau," Jurnal Teknik Informatika, Vol. 13, No 2, pp.1-6, 2018.

[11] Supardi, Metode Penelitian Ekonomi dan Bisnis. Yogyakarta: UII Press. 2005.

[12] Rosa A.S. M. Shalahudin, Rekayasa Perangkat Lunak. Bandung : Penerbit Modula. 2013.

[13] Pressman, Roger S. Rekayasa Perangkat Lunak. Penerbit Andi, Yogyakarta. 2012

[14] Sarwono, Jonathan., Metode Penelitian Kuantitatif dan Kualitatif. Yogyakarta: Graha Ilmu, 2006.

[15] W.O Galitz., The essential Guide to Unser Interface Design, Canada: John Wiley \& Sons. 2007 